Article

\title{
Preparation of Chloromethylated Pitch-Based Hyper-Crosslinked Polymers and An Immobilized Acidic Ionic Liquid as A Catalyst for the Synthesis of Biodiesel
}

\author{
Baoyou Pei ${ }^{1,2, \dagger}$, Xiaoyan Xiang ${ }^{1,+}$, Ting Liu ${ }^{2}$, Dongliang Li $^{3}$, Chaoyang Zhao ${ }^{2}$, Rongxing Qiu ${ }^{2}$, \\ Xiaoyan Chen ${ }^{1}$, Jinqing Lin ${ }^{1, *}$ and Xiaoyan Luo ${ }^{1, *}$ \\ 1 College of Materials Science and Engineering, Huaqiao University, Xiamen 361021, China; \\ pbylt1314@stu.hqu.edu.cn (B.P.); sandy006@hqu.edu.cn (X.X.); smilecxy123@163.com (X.C.) \\ 2 College of Chemical Engineering, Huaqiao University, Xiamen 361021, China; \\ 1t17013087014@stu.hqu.edu.cn (T.L.); zzy18134405387@163.com (C.Z.); xingstyle1001@163.com (R.Q.) \\ 3 School of foreign languages, Xinyu University, Xinyu 338000, China; airxygz@163.com \\ * Correspondence: linlab@hqu.edu.cn (J.L.); chemistrylxy@163.com (X.L.) \\ + These authors contributed equally to this work.
}

Received: 28 October 2019; Accepted: 12 November 2019; Published: 15 November 2019

\begin{abstract}
Hyper-crosslinking polymers and its immobilized acid ionic liquid catalyst were prepared using cheap pitch, as a monomer, through hyper-crosslinking reactions and allyl chloride, as a chlorine source, for chloromethylation and further grafting with imidazole and functionalizing with sulfonic acid. The polymers were characterized by FE-SEM, FTIR, TG, and nitrogen sorption. The grafting ratios of the chloromethylated pitch-based hyper-crosslinked polymer $\left(\mathrm{HCP}_{\text {pitch }}-\mathrm{CH}_{2}-\mathrm{Cl}\right)$ and immobilized acid ionic liquid [ $\left.\mathrm{HCP}_{\text {pitch }}-\mathrm{Im}-\mathrm{Pros}\right][\mathrm{Tos}]$ were $3.5 \mathrm{mmol} / \mathrm{g}$ and $3.0 \mathrm{mmol} / \mathrm{g}$, and the BET specific surface areas were $520 \mathrm{~m}^{2} / \mathrm{g}$ and $380 \mathrm{~m}^{2} / \mathrm{g}$, respectively. This strategy provides an easy approach to preparing highly stable and acid functionalized mesoporous catalysts. The immobilized acidic ionic liquid was used as a catalyst for the esterification of oleic acid and methanol to synthesize biodiesel. The results demonstrated that under the optimal conditions of an alcohol to acid molar ratio of 7:1, ionic liquid to oleic acid molar ratio of 0.12 , and a reaction time of $3 \mathrm{~h}$ at atmospheric pressure, the yield of methyl oleate can reach up to $93 \%$. Moreover, the catalyst was reused five times without the yield decreasing significantly. This study shows that $\left[\mathrm{HCP}_{\text {pitch }}-\mathrm{Im}-\mathrm{Pros}\right][\mathrm{Tos}]$ is a robust catalyst for the synthesis of biodiesel.
\end{abstract}

Keywords: immobilized acidic ionic liquid; hyper-crosslinked polymers; pitch; catalyst; biodiesel

\section{Introduction}

Due to the ongoing depletion of fossil fuel resources and serious environmental pollution, it is crucial to find a clean and renewable energy source [1,2]. As an alternative fuel for petrochemical diesel, biodiesel has been widely considered by domestic and foreign scholars because of its renewable and environmentally friendly advantages [3,4]. This so-called biodiesel is a general term for fatty acid methyl ester compounds which are mostly prepared by transesterification and esterification. However, conventional catalysts, such as concentrated sulfuric acid and $\mathrm{NaOH}$, have serious corrosion consequences for equipment, require higher acid values for raw materials, and are difficult to separate and recover. Therefore, there is an urgent need to research and develop economical and adaptable catalyst [5]. 
Motivated by these factors, ionic liquids are widely used in the catalytic synthesis of biodiesel due to the fact of their designable functional groups and the resulting acid-base adjustability. Notably, shortcomings, such as the high viscosity, result in slower diffusion mass transfer and difficulty in separation and recycling which greatly limit their industrial applications [6,7]. To this end, the immobilization of ionic liquids has become a trend and is applied in the synthesis of biodiesel. At present, immobilized ionic liquid catalysts include inorganic-supported catalysts [8], inorganic-organic hybrid catalysts [9], organic-supported catalysts [10], etc. However, there are still problems in the application of these catalysts, for instance, the complicated preparation process [11], the disappearance of active sites after many uses [12], and a lower specific surface area itself, resulting in lower graft density and fewer reactive sites [13]. In other words, it is necessary, to the largest degree, to increase the catalytic effect of the immobilized ionic liquid when designing the immobilized ionic liquid catalyst. Thus, three points need to be paid attention to: (1) how to design a carrier material that has a high tolerance to the chemical/physical environment and a low preparation cost to ensure that the carrier material will not react or decompose with the substrate in the catalytic process and which cannot reduce the activity of the catalyst; (2) that after the active center of the catalyst is bonded to the support material, more catalytic active centers are grafted as much as possible based on the bonding strength between the active center of the catalyst and the support material; and (3) the prepared catalyst should have a certain specific surface area, which ensures sufficient active catalytic sites [14].

As a kind of porous material, hyper-crosslinked polymers (HCPs) have become a good catalyst carrier material in recent years for their unique chemical stability, high specific surface area, and low skeletal density [15]. Most hyper-crosslinked polymers are prepared by Friedel-Crafts alkylation of aromatic ring monomers under the action of an external crosslinking agent so that the hyper-crosslinked polymer can be further functionalized by utilizing the properties of the aromatic ring [16-18]. In this process, the functionalization of HCPs is mainly based on the Blanco reaction to graft chloromethyl groups on the surface of HCPs and further to graft other catalytically active centers onto the HCPs through chloromethyl groups. However, at present, hydrochloric acid, as a chlorine source, is required to be introduced into the chloromethylation reaction-a process which is complicated and for which the amount of chloromethyl graft is not high [19].

Herein, we propose a strategy for preparing hyper-crosslinking polymers and their immobilized acid ionic liquid catalyst using cheap pitch as a monomer through a hyper-crosslinking reaction and allyl chloride as a chlorine source for chloromethylation, then grafting with imidazole and further functionalizing with sulfonic acid, as shown in Figure 1. A hyper-crosslinking polymer was prepared with cheap pitch as a monomer which will greatly reduce the preparation cost of the carrier material, and allyl chloride was used as a chlorine source which makes the reaction conditions for chloromethylation less harsh (Figure 1a). Moreover, the specific surface area of the prepared carrier material was relatively larger which provided favorable conditions for subsequent grafting of active functional centers on the carrier material. The prepared hyper-crosslinked polymer material that contained chloromethyl $\left(\mathrm{HCP}_{\text {pitch }}-\mathrm{CH}_{2}-\mathrm{Cl}\right)$ was grafted with imidazole and subsequently functionalized with sulfonic acid, then an immobilized acid ionic liquid [ $\left.\mathrm{HCP}_{\text {pitch }}-\mathrm{Im}-\mathrm{Pros}\right][\mathrm{Tos}]$ was obtained (Figure 1b).

The prepared immobilized acid ionic liquid $\left[\mathrm{HCP}_{\text {pitch }}-\mathrm{Im}-\mathrm{Pros}\right][\mathrm{Tos}]$ was used as a catalyst to catalyze the esterification between the oleic acid and methanol in order to synthesize biodiesel. A good amount of chloromethyl and a certain specific surface area ensure the sufficient amount of grafting imidazole sulfonate ionic liquid which increases the number of active sites and improves the catalytic effect. The results show that it is a robust catalyst for synthesis of biodiesel. 


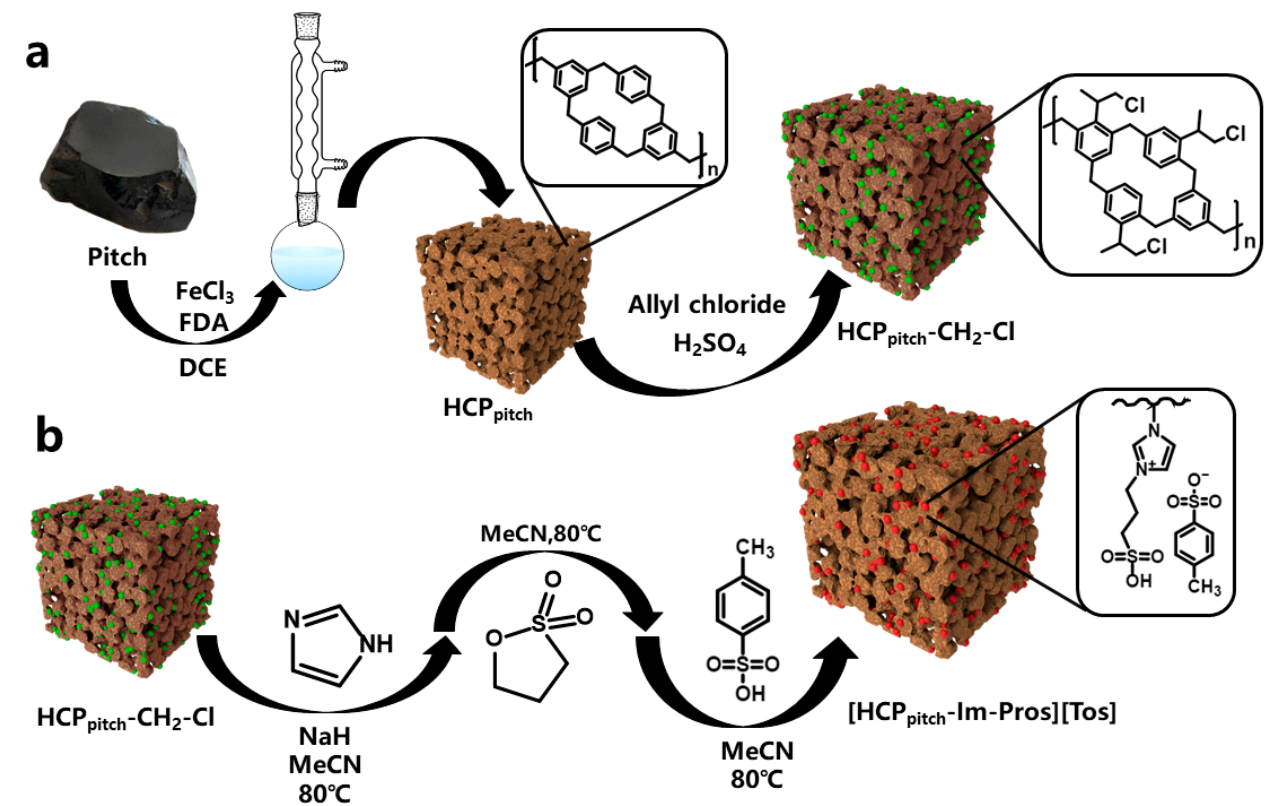

Figure 1. Schematic illustration of the synthesis of (a) $\mathrm{HCP}_{\text {pitch }}-\mathrm{CH}_{2}-\mathrm{Cl}$ and (b) $\left[\mathrm{HCP}_{\text {pitch}}-\mathrm{Im}-\mathrm{Pros}\right][\mathrm{Tos}]$ catalyst.

\section{Results and Discussion}

\subsection{Characterization of $\mathrm{HCP}_{\text {pitch }}-\mathrm{CH}_{2}-\mathrm{Cl}$ and [HCP pitch-Im-Pros][Tos]}

The FE-SEM images and the element mapping of the $\mathrm{HCP}_{\text {pitch }}, \mathrm{HCP}_{\text {pitch }}-\mathrm{CH}_{2}-\mathrm{Cl}$, and $\left[\mathrm{HCP}_{\text {pitch }}-\mathrm{Im}-\mathrm{Pros}\right][\mathrm{Tos}]$ are shown in Figure 2. It can be seen from Figure 2a,e, i that the as-prepared chloromethylated hyper-crosslinked polymer and the supported ionic liquid were amorphous porous structures, which was consistent with the subsequent specific surface analysis results. Comparing the results of Figure $2 b, f, j$, it can be concluded that the density of chlorine in $\mathrm{HCP}_{\text {pitch }}-\mathrm{CH}_{2}-\mathrm{Cl}$ was significantly higher than that of $\mathrm{HCP}_{\text {pitch }}-\mathrm{HCP}$, indicating that the chloromethyl group had been grafted successfully. Moreover, the density of chlorine in $\left[\mathrm{HCP}_{\text {pitch }}-\mathrm{Im}-\mathrm{Pros}\right][\mathrm{Tos}]$ was significantly reduced, indicating that chlorine was largely replaced and that chloromethyl and imidazolidine were alkylated. As shown in Figure $2 \mathrm{c}, \mathrm{g}$, both $\mathrm{HCP}_{\text {pitch }}$ and $\mathrm{HCP}_{\text {pitch }}-\mathrm{CH}_{2}-\mathrm{Cl}$ contained a small amount of $\mathrm{N}$ which may have come from the original pitch material. Interestingly, the nitrogen element in [ $\left.\mathrm{HCP}_{\text {pitch }}-\mathrm{Im}-\mathrm{Pros}\right][\mathrm{Tos}]$ (Figure $2 \mathrm{k}$ ) increased significantly, indicating that the imidazole group had been grafted successfully. Moreover, as can be seen from Figure $2 \mathrm{~d}, \mathrm{HCP}_{\text {pitch }}$ contained a lot of sulfur which may have also come from the original pitch material. While sulfur in $\mathrm{HCP}_{\text {pitch }}-\mathrm{CH}_{2}-\mathrm{Cl}$ (Figure 2h) was further increased, the reason may be that the sulfuric acid catalyst used in the chloromethylation process caused a small amount of sulfonation on the surface of the carrier. Also, the sulfur element in $\left[\mathrm{HCP}_{\text {pitch }}-\mathrm{Im}-\mathrm{Pros}\right][\mathrm{Tos}]$ (Figure 2i) was further increased, indicating that the carrier had been successfully attached to the sulfonic acid group, confirming that the immobilized ionic liquid had been successfully prepared. 


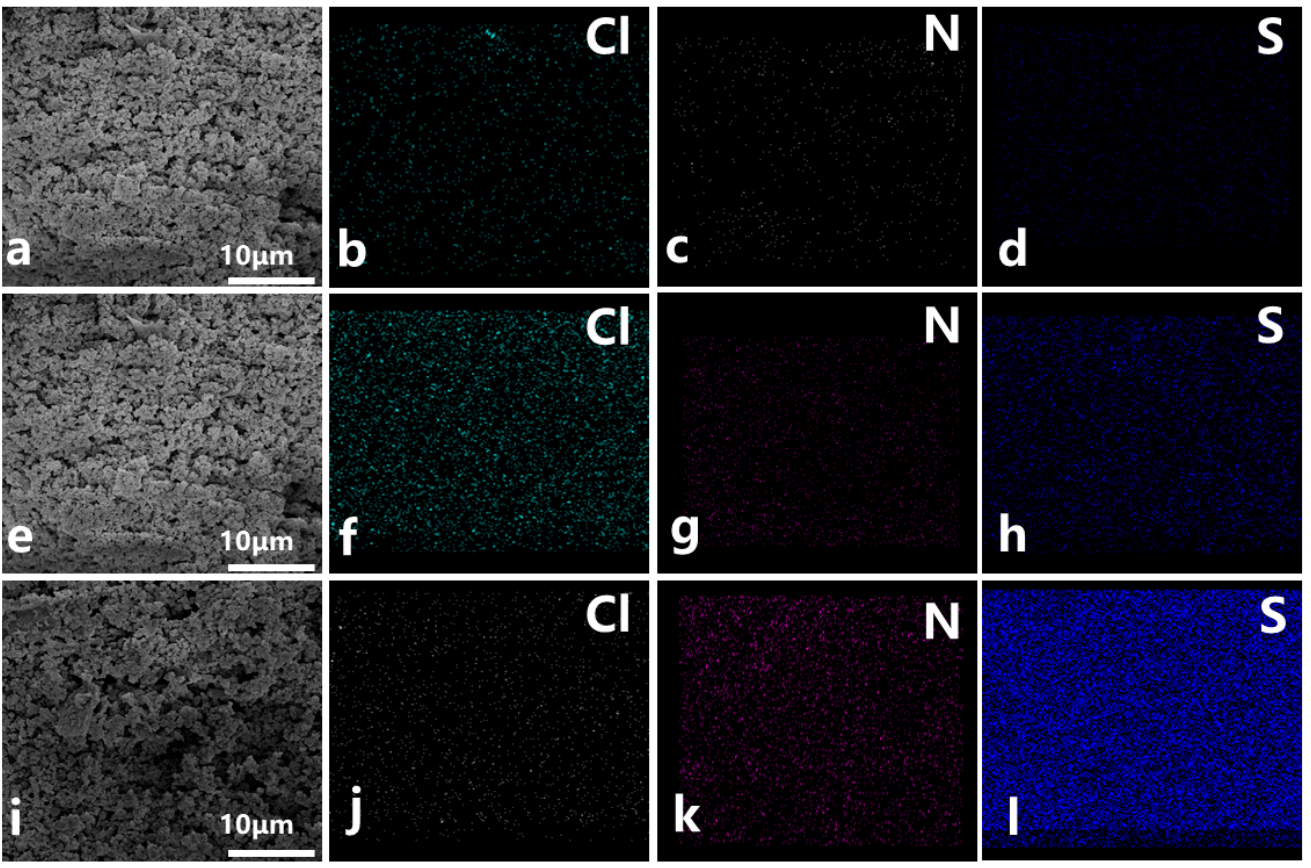

Figure 2. FE-SEM images of (a) $\mathrm{HCP}_{\text {pitch, }}$ (e) $\mathrm{HCP}_{\text {pitch }}-\mathrm{CH}_{2}-\mathrm{Cl}$, and (i) $\left[\mathrm{HCP}_{\text {pitch }}-\mathrm{Im}-\mathrm{Pros}\right][\mathrm{Tos}]$ catalyst. Element mappings of $\mathrm{HCP}_{\text {pitch }}, \mathrm{HCP}_{\text {pitch }}-\mathrm{CH}_{2}-\mathrm{Cl}$, and $\left[\mathrm{HCP}_{\text {pitch }}-\mathrm{Im}-\mathrm{Pros}\right][\mathrm{Tos}]:(\mathbf{b}, \mathbf{f}, \mathbf{j}) \mathrm{Cl}$, $(\mathbf{c}, \mathbf{g}, \mathbf{k}) \mathrm{N}$, and $(\mathbf{d}, \mathbf{h}, \mathbf{l}) \mathrm{S}$, respectively.

In order to further calculate the true content of the immobilized ionic liquid on the catalyst, an elemental analyzer was used to analyze the content of nitrogen and sulfur in the hyper-crosslinking polymer carrier, the chloromethylated carrier, and the immobilized ionic liquid; the results are shown in Table 1. The nitrogen contents in $\mathrm{HCP}_{\text {pitch }}, \mathrm{HCP}_{\text {pitch }}-\mathrm{CH}_{2}-\mathrm{Cl}$, and $[\mathrm{HCP}$ pitch-Im-Pros][Tos] were $0.21 \%$, $0.17 \%$, and $4.89 \%$, respectively, while the sulfur contents were $2.21 \%, 3.70 \%$, and $11.6 \%$, respectively. Not surprisingly, the results were consistent with the elemental mapping in Figure 2. Based on the calculation method for nitrogen content, the grafting ratio of the ionic liquid was calculated to be $3.0 \mathrm{mmol} / \mathrm{g}$.

Table 1. Elemental analysis of $\mathrm{HCP}_{\text {pitch }}, \mathrm{HCP}_{\text {pitch }}-\mathrm{CH}_{2}-\mathrm{Cl}$, and $\left[\mathrm{HCP}_{\text {pitch }}-\mathrm{Im}-\mathrm{Pros}\right][\mathrm{Tos}]$.

\begin{tabular}{lccc}
\hline \multicolumn{1}{c}{ Sample } & Percent 1 N (wt $\%)$ & Percent 2 S (wt $\%)$ & Grafting Degree (mmol/g) \\
\hline $\mathrm{HCP}_{\text {pitch }}$ & 0.21 & 2.21 & - \\
$\mathrm{HCP}_{\text {pitch }}-\mathrm{CH}_{2}-\mathrm{Cl}$ & 0.17 & 3.70 & - \\
{$\left[\mathrm{HCP}_{\text {pitch }}-\mathrm{Im}-\mathrm{Pros}\right][\mathrm{Tos}]$} & 4.89 & 11.6 & 3.0 \\
\hline
\end{tabular}

To further confirm the functional groups on the surface of the carrier, the FTIR spectra of $\mathrm{HCP}_{\text {pitch }}$ and $\mathrm{HCP}_{\text {pitch }}-\mathrm{CH}_{2}-\mathrm{Cl}$ were performed in Figure 3a. For $\mathrm{HCP}_{\text {pitch }}$, the weak $\mathrm{C}-\mathrm{H}$ stretching absorption of aromatic rings at $3040 \mathrm{~cm}^{-1}$ in $\mathrm{HCP}_{\text {pitch }}-\mathrm{CH}_{2}-\mathrm{Cl}$ was absent, while the characteristic peak of $\mathrm{C}-\mathrm{Cl}$ stretching at $620 \mathrm{~cm}^{-1}$ region was visible. These results confirm that the aromatic hydrogen atoms were substituted by allyl chloride.

The FTIR spectra of $\mathrm{HCP}_{\text {pitch }}-\mathrm{Im}-\mathrm{Pros},\left[\mathrm{HCP}_{\text {pitch }}-\mathrm{Im}-\mathrm{Pros}\right][\mathrm{Tos}]$, and Tos are shown in Figure $3 \mathrm{~b}$. It was found that the characteristic absorption bands of the sulfonic acid group at $1200 \mathrm{~cm}^{-1}, 1040 \mathrm{~cm}^{-1}$, and $801 \mathrm{~cm}^{-1}$ were due to the asymmetrical and symmetrical stretching vibrations of $\mathrm{S}-\mathrm{O}$ [13]. A weak peak at $1358 \mathrm{~cm}^{-1}$ can be assigned to the $\mathrm{C}-\mathrm{N}-\mathrm{C}$ stretching vibration showing the presence of an imidazole ring in the $\mathrm{HCP}_{\text {pitch }}-\mathrm{Im}-$ Pros [20]. Moreover, a broad and a strong band ranging from 3100 to $3500 \mathrm{~cm}^{-1}$ in $\left[\mathrm{HCP}_{\text {pitch }}-\mathrm{Im}-\mathrm{Pros}\right][\mathrm{Tos}]$ may be associated with the $-\mathrm{OH}$ stretching 
vibration [21]. These results indicate that the target $\left[\mathrm{HCP}_{\text {pitch }}-\mathrm{Im}-\mathrm{Pros}\right][\mathrm{Tos}]$ catalyst was obtained through the preparation.

a

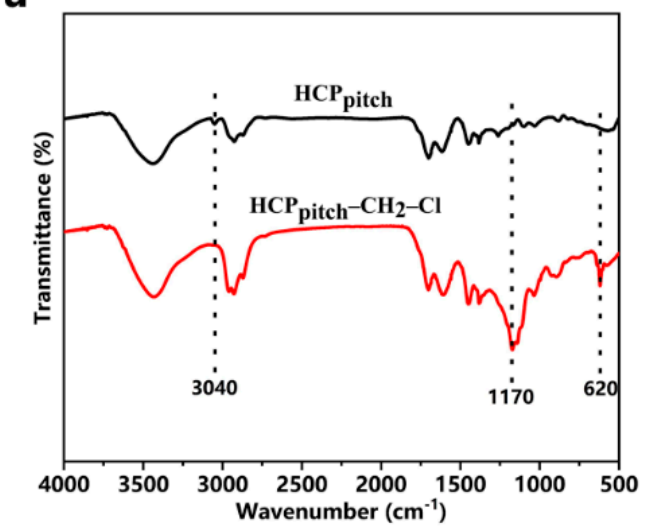

b

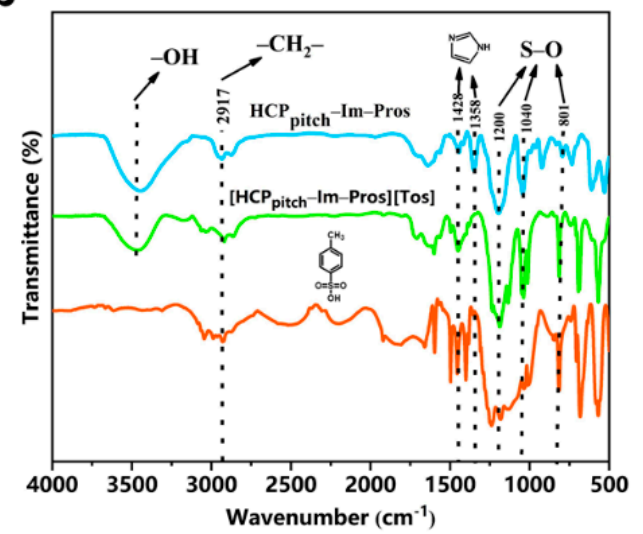

Figure 3. Fourier transform infrared (FTIR) spectra of samples: (a) $\mathrm{HCP}_{\text {pitch }}$ and $\mathrm{HCP}_{\text {pitch }}-\mathrm{CH}_{2}-\mathrm{Cl}$ and (b) $\mathrm{HCP}_{\text {pitch }}-\mathrm{Im}-$ Pros and $\left[\mathrm{HCP}_{\text {pitch }}-\mathrm{Im}-\right.$ Pros][Tos] catalyst.

Further, to ensure the thermal stability of the catalyst, thermogravimetric analysis of the immobilized acidic ionic liquid was conducted, as shown in Figure 4. The [ $\left.\mathrm{HCP}_{\text {pitch }}-\mathrm{Im}-\mathrm{Pros}\right][\mathrm{Tos}]$ exhibited good thermal stability and the thermal decomposition temperature was $235^{\circ} \mathrm{C}$. It should be noted that the framework of the catalyst carrier was prepared by Friedel-Crafts alkylation of aromatics in pitch. Therefore, the decomposition at $430{ }^{\circ} \mathrm{C}$ was mainly due to the decomposition of the framework of the catalyst carrier, namely, the decomposition of aromatics [22]. In this paper, the reaction temperature of oleic acid and methanol esterification to synthesize biodiesel was $70{ }^{\circ} \mathrm{C}$. This indicates that the immobilized ionic liquid can maintain thermal stability in the esterification reaction.

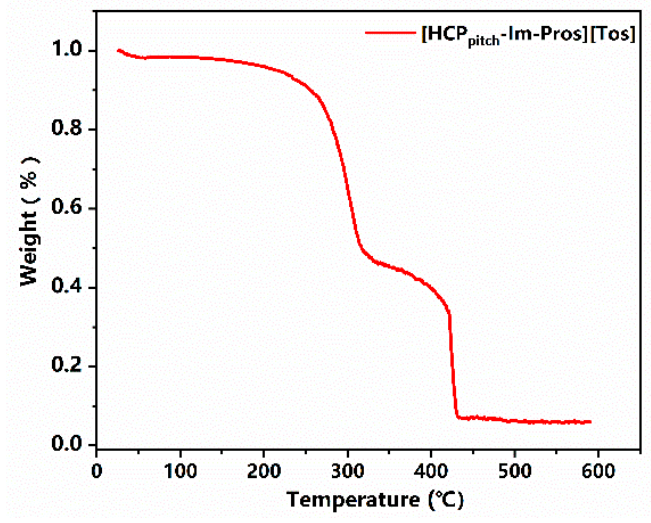

Figure 4. The TG curve of the $\left[\mathrm{HCP}_{\text {pitch }}-\mathrm{Im}-\mathrm{Pros}\right][\mathrm{Tos}]$ catalyst sample.

Moreover, the isothermal $\mathrm{N}_{2}$ adsorption-desorption test results for $\mathrm{HCP}_{\text {pitch }}-\mathrm{CH}_{2}-\mathrm{Cl}$ and $\left[\mathrm{HCP}_{\text {pitch }}-\mathrm{Im}-\mathrm{Pros}\right][\mathrm{Tos}]$ are shown in Figure 5. The results indicate that $\mathrm{HCP}_{\text {pitch }}-\mathrm{CH}_{2}-\mathrm{Cl}$ and $\left[\mathrm{HCP}_{\text {pitch-Im-Pros] }}\right.$ [Tos] successfully contained micropores and mesopores and illustrate that the dominant pore size of $\mathrm{HCP}_{\text {pitch }}-\mathrm{CH}_{2}-\mathrm{Cl}$ and $\left[\mathrm{HCP}_{\text {pitch }}-\mathrm{Im}-\mathrm{Pros}\right][\mathrm{Tos}]$ was $6.02 \mathrm{~nm}$ and $2.56 \mathrm{~nm}$, respectively. Similarly, the BET test results are shown in Table 2, and the specific surface area of HCP was $1153 \mathrm{~m}^{2} / \mathrm{g}$ which was $530 \mathrm{~m}^{2} / \mathrm{g}$ after chloromethylation and further reduced to $380 \mathrm{~m}^{2} / \mathrm{g}$ after grafting with ionic liquid. This was mainly due to the fact that the pores were blocked by the grafting ionic liquid [23]. 

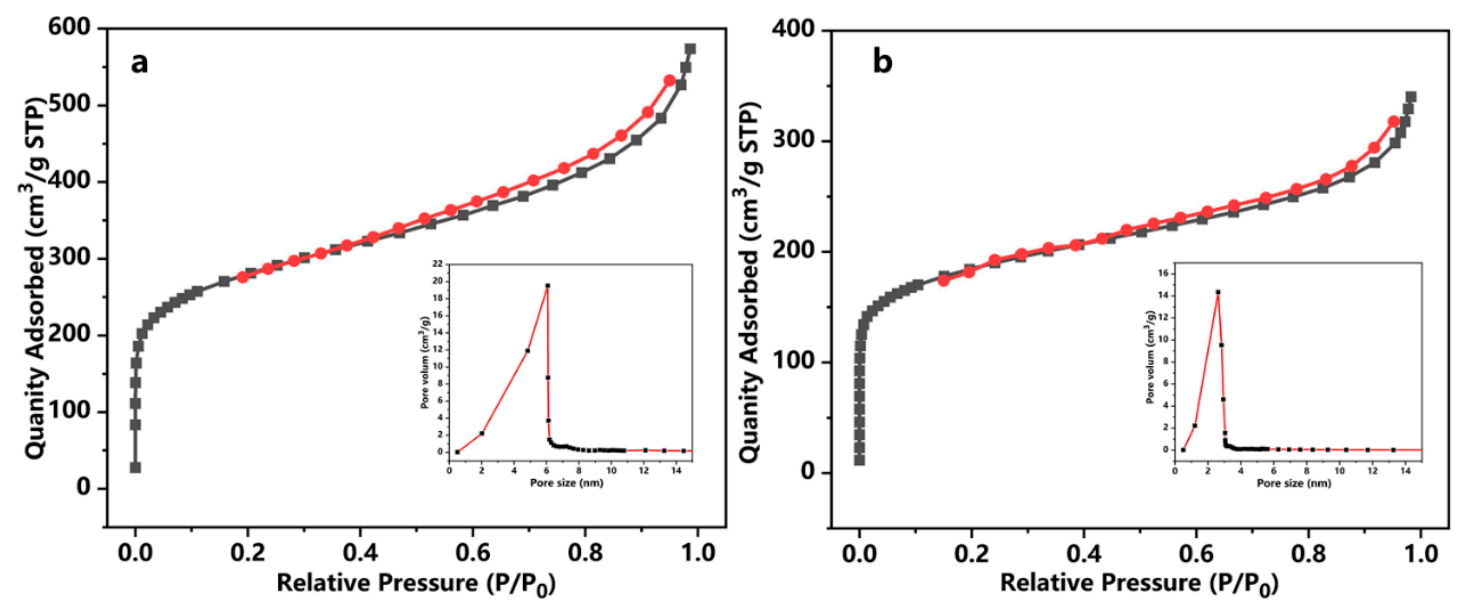

Figure 5. Nitrogen adsorption-desorption isotherms and pore size distributions (insert figures) for (a) $\mathrm{HCP}_{\text {pitch }}-\mathrm{CH}_{2}-\mathrm{Cl}$ and (b) $\left[\mathrm{HCP}_{\text {pitch }}-\mathrm{Im}-\mathrm{Pros}\right][\mathrm{Tos}]$.

Table 2. Surface area and porosity of $\mathrm{HCP}_{\text {pitch }}, \mathrm{HCP}_{\text {pitch }}-\mathrm{CH}_{2}-\mathrm{Cl}$, and $\left[\mathrm{HCP}_{\text {pitch }}-\mathrm{Im}-\mathrm{Pros}\right][\mathrm{Tos}]$.

\begin{tabular}{|c|c|c|c|c|c|}
\hline Sample & $\begin{array}{c}\mathrm{S}_{\mathrm{BET}}{ }^{\mathrm{a}} \\
\mathrm{m}^{2} / \mathrm{g}\end{array}$ & $\begin{array}{l}S_{L}{ }^{b} \\
m^{2} / g\end{array}$ & $\begin{array}{l}\text { M.A. } \\
\mathrm{m}^{2} / \mathrm{g}\end{array}$ & $\begin{array}{l}\mathrm{PV}^{\mathrm{d}} \\
\mathrm{cm}^{3} / \mathrm{g}\end{array}$ & $\begin{array}{c}\mathrm{MPV}^{\mathrm{e}} \\
\mathrm{cm}^{3} / \mathrm{g}\end{array}$ \\
\hline $\mathrm{HCP}_{\text {pitch }}$ & 1153 & 1291 & 672 & 1.89 & 0.22 \\
\hline $\mathrm{HCP}_{\text {pitch }}-\mathrm{CH}_{2}-\mathrm{Cl}$ & 530 & 613 & 310 & 0.47 & 0.19 \\
\hline$\left[\mathrm{HCP}_{\text {pitch }}-\mathrm{Im}-\mathrm{Pros}\right][\mathrm{Tos}]$ & 380 & 425 & 240 & 0.21 & 0.12 \\
\hline
\end{tabular}

a Surface area calculated from nitrogen adsorption isotherms at $77.3 \mathrm{~K}$ using the BET equation. ${ }^{\mathrm{b}}$ Surface area calculated from nitrogen adsorption isotherms at $77.3 \mathrm{~K}$ using the Langmuir equation. ${ }^{c}$ The t-plot micropore area.

$\mathrm{d}$ The total pore volume calculated from nitrogen isotherm at $\mathrm{P} / \mathrm{P} 0=0.995,77.3 \mathrm{~K}$. ${ }^{\mathrm{e}}$ The micropore volume derived

using the t-plot method based on the Halsey thickness equation.

\subsection{Influence of Chloromethylation Parameters on Chlorine Content of $\mathrm{HCP}_{\text {pitch }}-\mathrm{CH}_{2}-\mathrm{Cl}$}

After the preparation of $\mathrm{HCP}_{\text {pitch }}$ it was then modified with chloromethylation. We used allyl chloride as the chlorine source and concentrated sulfuric acid as the catalyst which not only avoided the use of hydrochloric acid generators in the traditional chloromethylation [24,25] but also obtained a higher chlorine content. The effects of adding the catalyst and allyl chloride and the reaction temperature and reaction time on the changes of the specific surface area and the chlorine content of the carrier were also investigated. All these results are shown in Figure 6.

As shown in Figure 6a, the chlorine content in $\mathrm{HCP}_{\text {pitch }}-\mathrm{CH}_{2}-\mathrm{Cl}$ gradually increased as the amount of catalyst increased, indicating that the grafting amount of the chloromethyl group gradually increased. However, when the amount of the catalyst exceeded a certain ratio, the chlorine content decreased which was due to the excess concentrated sulfuric acid causing more sulfonation reaction of the benzene ring on the carrier, and the sulfonic acid group occupied the position on the benzene ring so as to make the benzene ring passivated, resulting in a lower amount of chloromethylation [19]. The specific surface area of the prepared $\mathrm{HCP}_{\text {pitch }}-\mathrm{CH}_{2}-\mathrm{Cl}$ decreased with the increasing amount of the catalyst, because the grafted chloromethyl group occupied more and more pores as the graft amount increased. When the amount of the catalyst exceeded a certain ratio, although the grafting amount of the chloromethyl group decreased, the sulfonic acid group attached on the benzene ring through the continuously increasing sulfonation, and the pores were also occupied to further reduce the specific surface area.

Moreover, it can be seen from Figure $6 \mathrm{~b}$ that as the amount of allyl chloride increased, the chlorine content in $\mathrm{HCP}_{\text {pitch }}-\mathrm{CH}_{2}-\mathrm{Cl}$ increased sharply, indicating that the grafting amount of the chloromethyl groups increased rapidly. However, when the amount of allyl chloride exceeded a certain ratio, the chlorine content decreased because of an excess of allyl chloride which diluted the catalyst concentration, resulting in a smaller amount of chloromethylation. Also, the specific surface area of the 
prepared $\mathrm{HCP}_{\text {pitch }}-\mathrm{CH}_{2}-\mathrm{Cl}$ decreased with the increasing amount of allyl chloride; the reason for this phenomenon is that, in addition to the grafted chloromethyl group occupying the pores, the number of deposits formed from the carbonization of allyl chloride by concentrated sulfuric acid continuously increased, resulting in a further decrease in the specific surface area.

Furthermore, the results in Figure $6 \mathrm{c}$ show that the chlorine content in $\mathrm{HCP}_{\text {pitch }}-\mathrm{CH}_{2}-\mathrm{Cl}$ increased slowly with increasing temperature, indicating a slow increase in the grafting amount of chloromethyl groups. But, when the temperature was higher than $50{ }^{\circ} \mathrm{C}$, there was some decrease in the chlorine content because the chloromethylation was an exothermic reaction, resulting in a smaller amount of chloromethylation. The specific surface area of the prepared $\mathrm{HCP}_{\text {pitch }}-\mathrm{CH}_{2}-\mathrm{Cl}$ decreased with the increasing temperature because of the grafted chloromethyl group occupying the pores, and the amount of the deposit formed from the carbonization of allyl chloride by concentrated sulfuric acid drastically increased at a higher temperature, resulting in a further reduction in specific surface area. Moreover, Figure $6 \mathrm{~d}$ shows that the chlorine content in $\mathrm{HCP}_{\text {pitch }}-\mathrm{CH}_{2}-\mathrm{Cl}$ increased with the increasing reaction time. When the reaction time exceeded $24 \mathrm{~h}$, the chlorine content remained basically unchanged, indicating that the chloromethylation reaction had reached equilibrium. However, the specific surface area of the prepared $\mathrm{HCP}_{\text {pitch }}-\mathrm{CH}_{2}-\mathrm{Cl}$ continued to decrease after the reaction time exceeding $24 \mathrm{~h}$, which was because the amount of the deposit formed from allyl chloride carbonization by concentrated sulfuric acid was gradually increasing.

Collectively, under the optimum conditions, the mass ratio of $\mathrm{HCP}_{\text {pitch }}$ to propylene chloride was 1:5, the volume ratio of concentrated sulfuric acid to propylene chloride was 1:10, the reaction temperature was $50^{\circ} \mathrm{C}$, and the reaction time was $24 \mathrm{~h}$; the $\mathrm{HCP}_{\text {pitch }}-\mathrm{CH}_{2}-\mathrm{Cl}$ was successfully prepared with approximately $3.5 \mathrm{mmol} / \mathrm{g}$ of chlorine content which was much higher than the traditional methods.
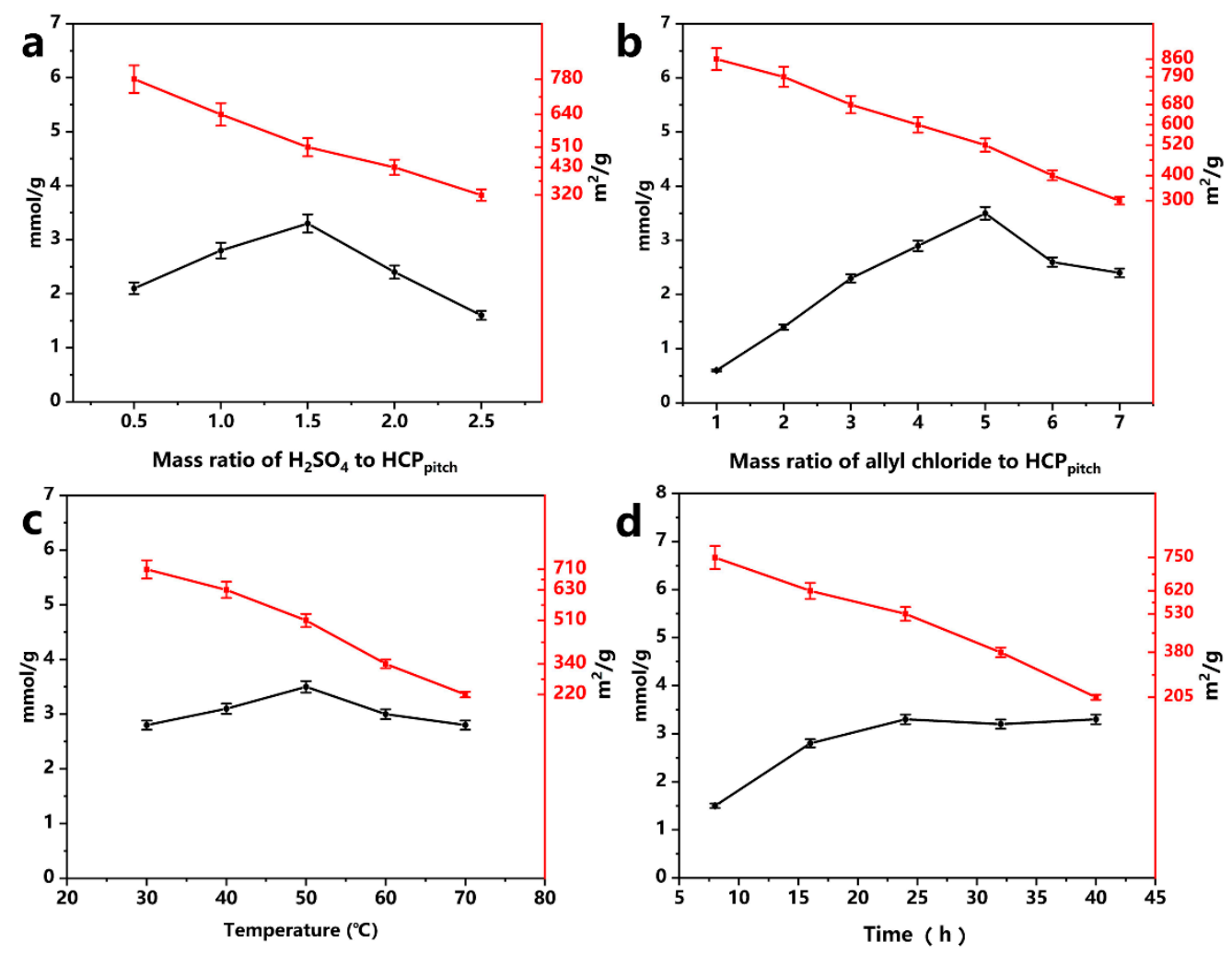

Figure 6. Impacts of four variables on the chloromethylation efficiency and the variation of specific surface area. (a) Additive amount of $\mathrm{H}_{2} \mathrm{SO}_{4}$, (b) additive amount of allyl chloride, (c) reaction temperature, $(\mathbf{d})$ reaction time. 


\subsection{Influence of Esterification Parameters on the Biodiesel Yield and Reusability of the Catalyst}

The as-prepared immobilized ionic liquid catalyst ([HCP $\mathrm{Hitch}-\mathrm{Im}-\mathrm{Pros}][\mathrm{Tos}])$ was used for the esterification of oleic acid and methanol to produce biodiesel, and the influence of the reaction time, the molar ratio of methanol and catalyst to oleic acid, and the reuse of the catalyst on the yield of biodiesel were investigated. The results are shown in Figure 7.

The effect of the reaction time on the yield of biodiesel is shown in Figure 7a. It was found that with the increase in reaction time, the yield of biodiesel increased initially; when the time reached $3 \mathrm{~h}$, the yield rapidly increased to $90.8 \%$. A further increase in the reaction time did not improve the yield of the biodiesel significantly; it might be limited by the chemical equilibrium of the reaction. Hence, the optimal reaction time was $3 \mathrm{~h}$ in this procedure. The results demonstrate that $\left[\mathrm{HCP}_{\text {pitch }}-\mathrm{Im}-\mathrm{Pros}\right][\mathrm{Tos}]$ is a robust catalyst for the esterification of oleic acid and methanol to synthesize biodiesel under atmospheric pressure within a short reaction time of less than $3 \mathrm{~h}$ at $70{ }^{\circ} \mathrm{C}$.

As can be seen from Figure $7 \mathrm{~b}$, the yield of biodiesel increased with the molar ratio of methanol to oleic acid. This may be related to the chemical equilibrium of the esterification reaction. The result illustrates that the optimal molar ratio of methanol to oleic acid in this heterogeneous reaction was greater than that in the homogeneous reaction with acid ionic liquid as the catalyst which might be that it was a heterogeneous reaction. However, it is interesting to note that the yield of biodiesel did not decrease with a further increase in the molar ratio of methanol to oleic acid, which was different from that in the homogeneous reaction system where the yield decreased when the molar ratio of methanol to oleic acid was greater than a certain value [26]. This means that excess methanol does not reduce the concentration of the catalyst in such a heterogeneous reaction system. The effect of the molar ratio of catalyst to oleic acid on the yield of biodiesel is shown in Figure 7c. Despite the fact that the yield of biodiesel was enhanced with the molar ratio of catalyst to oleic acid increasing from 0.04 to 0.12 , the yield of biodiesel did not increase when the amount of catalyst was further increased. It is worth noting that, when the molar ratio of catalyst to oleic acid increased, the reaction time did not increase anymore and which may have decreased due to the increase in viscosity.

To further investigate the reuse effect of the catalyst, the catalyst was first separated by filtration and washed with alcohol and water before the next run of the catalyst. As shown in Figure 7d, the catalyst was easily reused at least five times without significant loss in the product yield, indicating that $\left[\mathrm{HCP}_{\text {pitch }}-\mathrm{Im}-\mathrm{Pros}\right][\mathrm{Tos}]$ could be separated easily and still maintain catalytic activity, indicating that $\left[\mathrm{HCP}_{\text {pitch }}-\mathrm{Im}-\mathrm{Pros}\right][\mathrm{Tos}]$ can be a good catalyst in the esterification reaction of oleic acid and methanol to produce biodiesel.

Compared with other methods of preparing biodiesel (methyl oleate), the catalyst in this method was prepared from cheap and easily available pitch, and the prepared catalyst had a higher specific surface area and higher graft ratio of acidic ionic liquid which can not only shorten the reaction time but also reduce the production cost. 

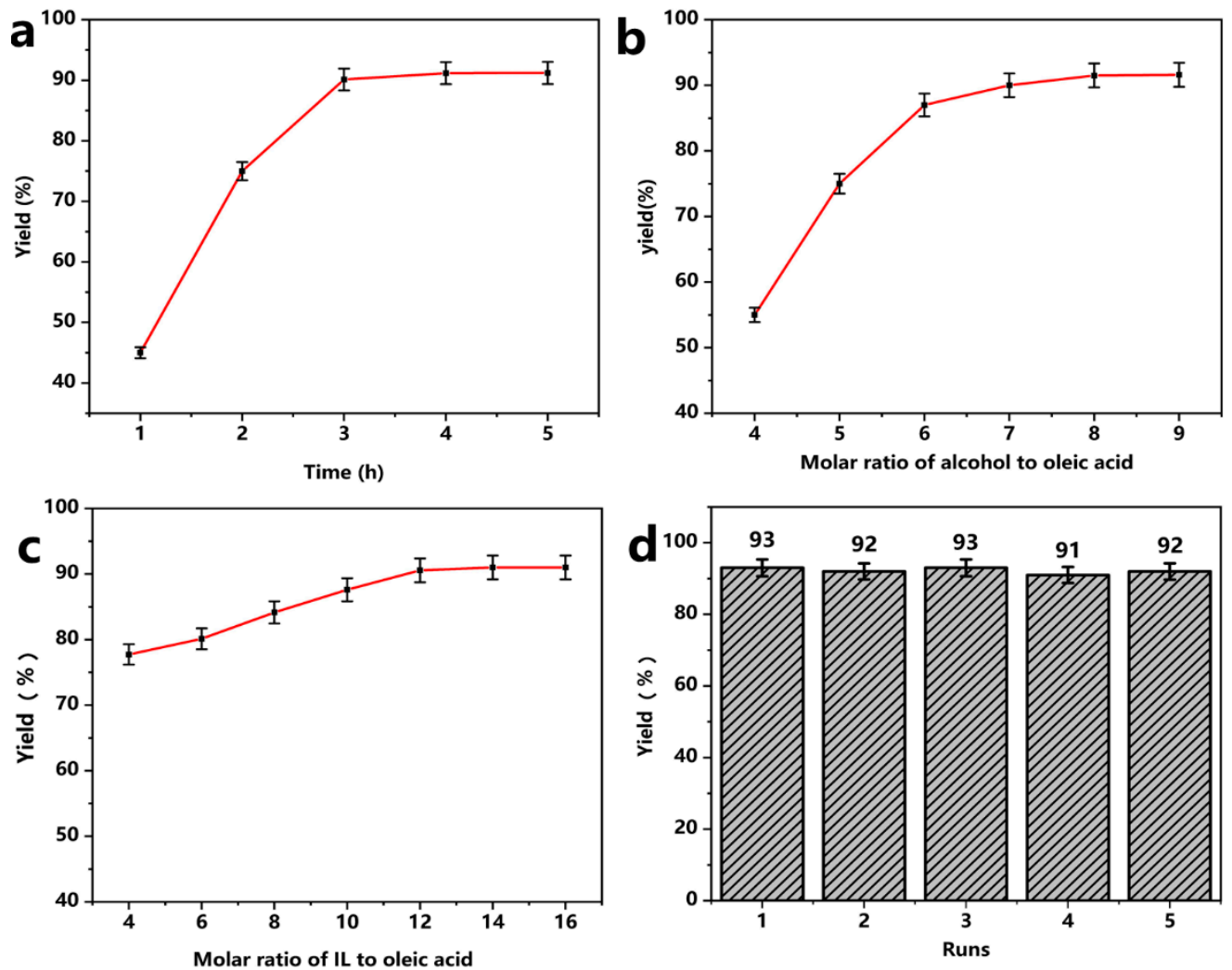

Figure 7. Impacts of reaction parameters on biodiesel production catalyzed by [ $\left.\mathrm{HCP}_{\text {pitch }}-\mathrm{Im}-\mathrm{Pros}\right][\mathrm{Tos}]$. (a) 2.82 g oleic acid; $8 \%$ catalyst amount; $\mathrm{n}$ (methanol):n (oleic acid) $=7: 1 ; 3 \mathrm{~h}$; (b) 8\% catalyst amount; $3 \mathrm{~h} ; 70{ }^{\circ} \mathrm{C}$; (c) $2.82 \mathrm{~g}$ oleic acid; $3 \mathrm{~h} ; \mathrm{n}$ (methanol):n (oleic acid) $=7: 1 ; 70{ }^{\circ} \mathrm{C}$; (d) $14.1 \mathrm{~g}$ oleic acid, $1.0 \mathrm{~g}$ $\left[\mathrm{HCP}_{\text {pitch }}\right.$-Im-Pros][Tos], molar ratio of methanol to oleic acid $=7: 1,70{ }^{\circ} \mathrm{C}, 3 \mathrm{~h}$.

\section{Materials and Methods}

\subsection{Materials}

Petroleum pitch (PLP) was obtained from Lidun Road Project Co., Ltd. (JiangSu, China) (consisting of $20.7 \%$ asphaltenes (As), $27.9 \%$ saturates (S), 39.7\% aromatics (Ar), and $12.2 \%$ resins (R); element contents were C: $92.37 \%, \mathrm{H}: 7.10 \%, \mathrm{~N}: 0.18 \%, \mathrm{O}: 0.35 \%, \mathrm{C} / \mathrm{H}=13$; softening point was $195{ }^{\circ} \mathrm{C}$ ). Iron (III)chlorideanhydrous $\left(\mathrm{FeCl}_{3}\right)$, sodium hydride $(\mathrm{NaH})$ and allyl chloride were obtained from Aladdin Bio-Chem Technology Co., Ltd. (Shanghai, China). Ethanol, methanol, 1,2-dichloroethane (DEC), ethyl acetate (AcOEt), dimethoxymethane (FDA), acetonitrile $\left(\mathrm{CH}_{3} \mathrm{CN}\right)$, sulfuric acid, imidazole, p-toluenesulfonic acid, and calcium chloride anhydrous $\left(\mathrm{CaCl}_{2}\right)$ were purchased from Sinopharm chemical reagent Co., Ltd. (Shanghai, China). Oleic acid and 1,3-propanesultone were purchased from Xiya reagent Co., Ltd. (Shandong, China). The DEC was dried with $\mathrm{CaH}_{2}$ overnight, and subsequently distilled. Unless specifically noted, all the chemical reagents were of analytical grade and used as received without further purification.

\subsection{Preparation of Catalysis}

The $\mathrm{HCP}_{\text {pitch }}$ was synthesized using the method shown in Figure 1a. It was functionalized by allyl chloride to obtain a super crosslinked porous polymer $\left(\mathrm{HCP}_{\text {pitch }}-\mathrm{CH}_{2}-\mathrm{Cl}\right)$ containing chloromethyl groups on the surface. The immobilized acid ionic liquid catalyst $\left[\mathrm{HCP}_{\text {pitch }}-\mathrm{Im}-\mathrm{Pros}\right][\mathrm{Tos}]$ was obtained by grafting the sulfonate ionic liquid with the $\mathrm{HCP}_{\text {pitch }}-\mathrm{CH}_{2}-\mathrm{Cl}$ as a carrier, as shown in Figure $1 \mathrm{~b}$. 


\subsubsection{Preparation of $\mathrm{HCP}_{\text {pitch }}$}

The $\mathrm{HCP}_{\text {pitch }}$ was prepared according to a previously described method [27]. Notably, under a nitrogen atmosphere, petroleum pitch $(2.0 \mathrm{~g})$ was added into $50 \mathrm{~mL}$ DEC in a round-bottomed flask. The FDA ( $0.06 \mathrm{~mol}, 4.566 \mathrm{~g})$ was added and then stirred for $20 \mathrm{~min}$. The $\mathrm{FeCl}_{3}(0.06 \mathrm{~mol}, 9.732 \mathrm{~g})$ was added to the round-bottomed flask. Then the reaction proceeded at $50{ }^{\circ} \mathrm{C}$ for $10 \mathrm{~h}$ and then at $80^{\circ} \mathrm{C}$ for $14 \mathrm{~h}$. After the reaction, the reaction mixture was poured into $150 \mathrm{~mL}$ ethanol in a beaker and cooled down to room temperature, and the solid product was washed with methyl alcohol and treated with vacuum filtering three times. The final product was dried in a vacuum at $80^{\circ} \mathrm{C}$ for $24 \mathrm{~h}$.

\subsubsection{Preparation of $\mathrm{HCP}_{\text {pitch }}-\mathrm{CH}_{2}-\mathrm{Cl}$}

The $\mathrm{HCP}_{\text {pitch }}(1.5 \mathrm{~g})$, allyl chloride $(0.098 \mathrm{~mol}, 7.5 \mathrm{~g})$, and $98 \% \mathrm{H}_{2} \mathrm{SO}_{4}(2.25 \mathrm{~g})$ were added into $50 \mathrm{~mL}$ DEC in a round-bottomed flask consecutively. The resulting mixture was heated at $45^{\circ} \mathrm{C}$ for $12 \mathrm{~h}$. After cooling to room temperature, the solid product was washed with methanol three times and treated with vacuum filtering. Finally, the obtained powder was dried in a vacuum at $70^{\circ} \mathrm{C}$ for $12 \mathrm{~h}$. The functionalized material of $\mathrm{HCP}_{\text {pitch }}-\mathrm{CH}_{2}-\mathrm{Cl}$ was obtained as a dark brown solid.

\subsubsection{Preparation of $\left[\mathrm{HCP}_{\text {pitch }}-\mathrm{Im}-\mathrm{Pros}\right][\mathrm{Tos}]$}

The $\mathrm{HCP}_{\text {pitch }}-\mathrm{CH}_{2}-\mathrm{Cl}(3.0 \mathrm{~g})$ as a substrate was added into $80 \mathrm{~mL}$ acetonitrile in a round-bottomed flask and then imidazole $(0.017 \mathrm{~mol})$ was added to the mixture and then stirred for $20 \mathrm{~min}$. A certain amount of $\mathrm{NaH}(0.018 \mathrm{~mol})$ was added to the round-bottomed flask. Then the reaction proceeded at $80^{\circ} \mathrm{C}$ for $48 \mathrm{~h}$. The formation of white precipitate was detected by acidifying silver nitrate solution. After cooling to room temperature, the product was washed with methanol three times and treated with vacuum filtering; thus, the $\mathrm{HCP}_{\text {pitch }}-\mathrm{CH}_{2}-\mathrm{Im}$ was prepared.

The prepared $\mathrm{HCP}_{\text {pitch }}-\mathrm{CH}_{2}-\mathrm{Im}$ and the 1,3-propanesultone $(0.018 \mathrm{~mol})$ were added into a round-bottomed flask, then $50 \mathrm{~mL}$ acetonitrile was added as a solvent. After the reaction proceeded for $48 \mathrm{~h}$ at $80^{\circ} \mathrm{C}$, the product was filtered and washed three times with methyl alcohol, and the brown solid $\mathrm{HCP}_{\text {pitch }}$-Im-Pros was obtained. After filtering to a constant pressure, the brown solid and 1,3-p-toluenesulfonic acid $(0.02 \mathrm{~mol})$ were added into $50 \mathrm{~mL}$ acetonitrile in a round-bottomed flask; the reaction was allowed to proceed at $80^{\circ} \mathrm{C}$ for $24 \mathrm{~h}$ and the obtained precipitate was washed three times with methyl alcohol and further purified using Soxhlet extractor with ethyl acetate as an extraction reagent for $24 \mathrm{~h}$. Finally, $\left[\mathrm{HCP}_{\text {pitch}}-\mathrm{Im}-\mathrm{Pros}\right][\mathrm{Tos}]$ was prepared.

\subsection{Determination of Grafting Ratio of Chloromethyl}

The $\mathrm{HCP}_{\text {pitch }}-\mathrm{CH}_{2}-\mathrm{Cl}(1.0 \mathrm{~g})$ was added into $30 \mathrm{~mL}$ acetonitrile in a round-bottomed flask and then imidazole $(0.01 \mathrm{~mol})$ was added to the mixture and stirred for $20 \mathrm{~min}$. The $\mathrm{NaH}(0.012 \mathrm{~mol})$ was added to the round-bottomed flask. Then, the reaction proceeded at $80^{\circ} \mathrm{C}$ for $48 \mathrm{~h}$. After the reaction of $\mathrm{HCP}_{\text {pitch }}-\mathrm{CH}_{2}-\mathrm{Cl}$ with imidazole, the filtrate obtained was moved into a conical flask with $5 \mathrm{~mL}$ distilled water. The mixture was stirred rapidly at room temperature and the $\mathrm{pH}$ value was adjusted to less than 8 in a cone bottle using the diluted nitric acid. Then, silver nitrate standard solution $\left(\mathrm{C}_{\mathrm{AgNO} 3}\right.$ $=0.1000 \mathrm{~mol} / \mathrm{L})$, as a titrant, and potassium dichromate solution $(5 \mathrm{wt} \%)$, as an indicator, were used to titrate the mentioned mixture solution. When the indicator was discolored, the volume of $\mathrm{AgNO}_{3}$ consumed was recorded as $\mathrm{V}$. The grafting ratio of chloromethyl in $\mathrm{HCP}_{\text {pitch }}-\mathrm{CH}_{2}-\mathrm{Cl}$ was able to be determined using this method.

\subsection{Characterization}

Infrared spectra were recorded on a Fourier transform infrared spectroscopy (FTIR) spectrometer (Thermo Scientific Nicolet410, Thermo Electron Instruments Co., Shanghai, China). To observe the surface morphology, energy-dispersive X-ray spectroscopy (EDS, OXFORD 51-XMX, Oxford, UK) assisted field-emission scanning electron microscopy (FE-SEM, HITACHI S-4800, Tokyo, Japan) was 
used, and the thermogravimetric analysis (TGA) of the materials was conducted on a TA Instruments Q50 (US) thermal analyzer at a heating rate of $5{ }^{\circ} \mathrm{C} / \mathrm{min}$ in air. Nitrogen adsorption-desorption isotherms were recorded using Micrometric (ASAP 2020 apparatus, Norcross, GA, USA).

\subsection{Preparation of Biodiesel}

The oleic acid, methanol, and $\left[\mathrm{HCP}_{\text {pitch }}\right.$-Im-Pros][Tos] were added to a $50 \mathrm{~mL}$ flask with a reflux condenser and a magnetic stir bar. The mixture was heated rapidly to the desired temperature in an oil bath to synthesize biodiesel (Figure 8). When the reaction finished, the mixture was cooled at room temperature. Finally, the solid catalyst was filtered from the solution, and the filtrate was moved into a volumetric flask and diluted with ethanol to $100 \mathrm{~mL}$. Experiments were carried out to optimize the variables for the esterification process, such as the molar ratio of methanol to oleic acid, the molar ratio of catalyst to oleic acid, reaction time, and reaction temperature.

$$
\mathrm{CH}_{3}\left(\mathrm{CH}_{2}\right)_{7} \mathrm{CH}=\mathrm{CH}\left(\mathrm{CH}_{2}\right)_{7} \mathrm{COOH}+\mathrm{CH}_{3} \mathrm{OH} \stackrel{\text { catalyst }}{\underset{\triangle}{\rightleftharpoons}} \mathrm{CH}_{3}\left(\mathrm{CH}_{2}\right)_{7} \mathrm{CH}=\mathrm{CH}\left(\mathrm{CH}_{2}\right)_{7} \mathrm{COOCH}_{3}+\mathrm{H}_{2} \mathrm{O}
$$

Figure 8. Synthesis of biodiesel through esterification of oleic acid with methanol using prepared catalyst.

\subsection{GC Analysis and Biodiesel Yield}

The products of the methyl ester contents in the reaction mixture were quantified by a GC-7890B gas chromatograph (Agilent, Santa Clara, CA, US) using a HP-INNOWAX capillary column (60 m $\times 0.320 \mathrm{~mm}$ i.d.; film thickness $0.25 \mu \mathrm{m}$ ) connected to a flame ionization detector (FID). The oven temperature was kept at $130^{\circ} \mathrm{C}$ for $1 \mathrm{~min}$, raised to $160^{\circ} \mathrm{C}$ at $10^{\circ} \mathrm{C} / \mathrm{min}$, maintained at this temperature for $1 \mathrm{~min}$, elevated to $210^{\circ} \mathrm{C}$ at $20^{\circ} \mathrm{C} / \mathrm{min}$, and then increased to $250{ }^{\circ} \mathrm{C}$ at $10{ }^{\circ} \mathrm{C} / \mathrm{min}$ and held for $11.5 \mathrm{~min}$. The temperatures of the injector and detector were set at $280^{\circ} \mathrm{C}$. The split ratio was $40: 1$, and pure nitrogen was used as a carrier gas. The concentration of methyl oleate in the samples was analyzed by an external standard method, and each sample was analyzed three times. The biodiesel yield can be calculated with the concentration of methyl oleate in the sample.

\section{Conclusions}

Hyper-crosslinking polymers and their immobilized acid ionic liquid catalyst were successfully prepared using cheap pitch, as a monomer, through hyper-crosslinking reactions and allyl chloride, as a chlorine source, for chloromethylation and further grafting with imidazole and functionalizing with sulfonic acid. The results showed that the grafting ratios of hyper-crosslinked polymer $\left(\mathrm{HCP}_{\text {pitch }}-\mathrm{CH}_{2}-\mathrm{Cl}\right)$ and immobilized acid ionic liquid $\left[\mathrm{HCP}_{\text {pitch }}-\mathrm{Im}-\mathrm{Pros}\right][\mathrm{Tos}]$ were $3.5 \mathrm{mmol} / \mathrm{g}$ and $3.0 \mathrm{mmol} / \mathrm{g}$, and the BET specific surface areas were $520 \mathrm{~m}^{2} / \mathrm{g}$ and $380 \mathrm{~m}^{2} / \mathrm{g}$, respectively. The immobilized acidic ionic liquid [ $\left.\mathrm{HCP}_{\text {pitch }}-\mathrm{Im}-\mathrm{Pros}\right][\mathrm{Tos}]$ was used as a catalyst for the esterification of oleic acid and methanol to synthesize biodiesel. The results demonstrate that, under the optimal conditions of a molar ratio of alcohol to acid at 7:1, a molar ratio of ionic liquid to oleic acid of 0.12, and a reaction time of $3 \mathrm{~h}$, the yield of methyl oleate could reach up to $93 \%$. Moreover, the catalyst was reused five times without any significantly decrease in the yield. All these results illustrate that $\left[\mathrm{HCP}_{\text {pitch-Im-Pros }][T o s]}\right.$ is a robust catalyst for the synthesis of biodiesel.

In summary, this work provides a new easy strategy to prepare high grafting ratio and acid functionalized mesoporous catalysts for synthesis of biodiesel. Meanwhile, the carrier prepared by the pitch has the advantages of being cheap and easy to obtain which can greatly reduce the cost of the immobilized ionic liquid and is beneficial to popularizing the preparation of the catalytic carrier of the immobilized ionic liquid and can be promoted and applied in related fields.

Author Contributions: B.P. and X.X. conceived and designed the experiments; B.P., C.Z. and T.L. implemented the experiments and wrote the paper; X.C. and R.Q. analyzed the data; B.P. and D.L. contributed to the revision and proofreading of the manuscript; writing - review \& editing, J.L. and X.L. 
Funding: This research was funded by the National Natural Science Foundation of China (grant nos. 21803021, 21246008) and the Subsidized Project for Postgraduates' Innovative Fund in Scientific Research of Huaqiao University.

Acknowledgments: We gratefully acknowledge the financial support of this work from the National Natural Science Foundation of China $(21803021,21246008)$ and the Subsidized Project for Postgraduates' Innovative Fund in Scientific Research of Huaqiao University.

Conflicts of Interest: The authors declare no conflict of interest.

\section{References}

1. Aghbashlo, M.; Hosseinpour, S.; Tabatabaei, M.; Mojarab Soufiyan, M. Multi-objective exergetic and technical optimization of a piezoelectric ultrasonic reactor applied to synthesize biodiesel from waste cooking oil (WCO) using soft computing techniques. Fuel 2019, 235, 100-112. [CrossRef]

2. Hosseinzadeh-Bandbafha, H.; Tabatabaei, M.; Aghbashlo, M.; Khanali, M.; Demirbas, A. A comprehensive review on the environmental impacts of diesel/biodiesel additives. Energy Convers. Manag. 2018, 174, 579-614. [CrossRef]

3. Sánchez-Bayo, A.; Morales, V.; Rodríguez, R.; Vicente, G.; Bautista, L. Biodiesel Production (FAEEs) by Heterogeneous Combi-Lipase Biocatalysts Using Wet Extracted Lipids from Microalgae. Catalysts 2019, 9, 296. [CrossRef]

4. Zhang, C.; Shao, W.; Zhou, W.; Liu, Y.; Han, Y.; Zheng, Y.; Liu, Y. Biodiesel Production by Esterification Reaction on K+ Modified MgAl-Hydrotalcites Catalysts. Catalysts 2019, 9, 742. [CrossRef]

5. Shamun, S.; Belgiorno, G.; Di Blasio, G.; Beatrice, C.; Tunér, M.; Tunestål, P. Performance and emissions of diesel-biodiesel-ethanol blends in a light duty compression ignition engine. Appl. Therm. Eng. 2018, 145, 444-452. [CrossRef]

6. Qiu, T.; Guo, X.; Yang, J.; Zhou, L.; Li, L.; Wang, H.; Niu, Y. The synthesis of biodiesel from coconut oil using novel Brønsted acidic ionic liquid as green catalyst. Chem. Eng. J. 2016, 296, 71-78. [CrossRef]

7. Yang, Z.; Cui, X.; Jie, H.; Yu, X.; Zhang, Y.; Feng, T.; Liu, H.; Song, K. Kinetic Study and Process Simulation of Transesterification of Methyl Acetate and Isoamyl Alcohol Catalyzed by Ionic Liquid. Ind. Eng. Chem. Res. 2015, 54, 1204-1215. [CrossRef]

8. Li, J.; Peng, X.; Luo, M.; Zhao, C.-J.; Gu, C.-B.; Zu, Y.-G.; Fu, Y.-J. Biodiesel production from Camptotheca acuminata seed oil catalyzed by novel Brönsted-Lewis acidic ionic liquid. Appl. Energy 2014, 115, 438-444. [CrossRef]

9. Han, M.J.; Li, Y.; Gu, Z.; Shi, H.L.; Chen, C.; Wang, Q.; Wan, H.; Guan, G.F. Immobilization of thiol-functionalized ionic liquids onto the surface of MIL-101(Cr) frameworks by S-Cr coordination bond for biodiesel production. Colloids Surf. A Physicochem. Eng. Asp. 2018, 553, 593-600. [CrossRef]

10. Pan, H.; Li, H.; Zhang, H.; Wang, A.; Yang, S. Acidic ionic liquid-functionalized mesoporous melamine-formaldehyde polymer as heterogeneous catalyst for biodiesel production. Fuel 2019, 239, 886-895. [CrossRef]

11. Lisboa, M.C.; Rodrigues, C.A.; Barbosa, A.S.; Mattedi, S.; Freitas, L.S.; Mendes, A.A.; Dariva, C.; Franceschi, E.; Lima, A.S.; Soares, C.M.F. New perspectives on the modification of silica aerogel particles with ionic liquid used in lipase immobilization with platform in ethyl esters production. Process Biochem. 2018, 75, 157-165. [CrossRef]

12. Xie, W.L.; Wan, F. Immobilization of polyoxometalate-based sulfonated ionic liquids on UiO-66-2COOH metal-organic frameworks for biodiesel production via one-pot transesterification-esterification of acidic vegetable oils. Chem. Eng. J. 2019, 365, 40-50. [CrossRef]

13. Wang, K.; Jia, Z.; Yang, X.; Wang, L.; Gu, Y.; Tan, B. Acid and base coexisted heterogeneous catalysts supported on hyper-crosslinking polymers for one-pot cascade reactions. J. Catal. 2017, 348, 168-176. [CrossRef]

14. Bhunia, S.; Banerjee, B.; Bhaumik, A. A new hypercrosslinked supermicroporous polymer, with scope for sulfonation, and its catalytic potential for the efficient synthesis of biodiesel at room temperature. Chem. Commun. 2015, 51, 5020-5023. [CrossRef] [PubMed]

15. Li, B.; Zhang, Y.; Ma, D.; Shi, Z.; Ma, S. Mercury nano-trap for effective and efficient removal of mercury(II) from aqueous solution. Nat. Commun. 2014, 5, 5537. [CrossRef] 
16. Xu, S.; Luo, Y.; Tan, B. Recent development of hypercrosslinked microporous organic polymers. Macromol. Rapid Commun. 2013, 34, 471-484. [CrossRef]

17. Tan, L.; Tan, B. Hypercrosslinked porous polymer materials: Design, synthesis, and applications. Chem. Soc. Rev. 2017, 46, 3322-3356. [CrossRef]

18. Wang, X.; Mu, P.; Zhang, C.; Chen, Y.; Zeng, J.; Wang, F.; Jiang, J.X. Control Synthesis of Tubular Hyper-Cross-Linked Polymers for Highly Porous Carbon Nanotubes. ACS Appl. Mater. Interfaces 2017, 9 , 20779-20786. [CrossRef]

19. Teixeira, V.G.; Coutinho, F.M.B. Morphological study on the reactivity of styrene-divinylbenzene copolymers in a chloromethylation reaction. J. Appl. Polym. Sci. 2010, 26, 14849-14866. [CrossRef]

20. Wu, J.; Gao, Y.; Zhang, W.; Tang, A.; Tan, Y.; Men, Y.; Tang, B. New imidazole-type acidic ionic liquid polymer for biodiesel synthesis from vegetable oil. Chem. Eng. Process. Process Intensif. 2015, 93, 61-65. [CrossRef]

21. Karimi, B.; Vafaeezadeh, M. SBA-15 functionalized sulfonic acid containing a confined hydrophobic and acidic ionic liquid: A highly efficient catalyst for solvent-free thioacetalization of carbonyl compounds at room temperature. RSC Adv. 2013, 3, 23207. [CrossRef]

22. Xu, Z.; Wan, H.; Miao, J.; Han, M.; Yang, C.; Guan, G. Reusable and efficient polystyrene-supported acidic ionic liquid catalyst for esterifications. J. Mol. Catal. Chem. 2010, 332, 152-157. [CrossRef]

23. Dragan, E.S.; Avram, E.; Axente, D.; Marcu, C. Ion-exchange resins. III. Functionalization-morphology correlations in the synthesis of some macroporous, strong basic anion exchangers and uranium-sorption properties evaluation. J. Polym. Sci. Part A Polym. Chem. 2004, 42, 2451-2461. [CrossRef]

24. Chen, Z.B.; Kang, L.; Di, D.L.; Dong, F.; Yu, H. Chloromethylation Research of LX-1180 Macroporous Adsorption Resin in Ultrasonic Environment. Adv. Mater. Res. 2011, 233-235, 2893-2897. [CrossRef]

25. Fu, Y.; Huang, X.; Zhong, S.; Yi, W.-J.; Li, L.-J. A new chloromethylation method based on polystyrene-divinylbenzene. Chem. Pap. 2019, 73, 2183-2188. [CrossRef]

26. Qi, J.; Lin, J.; Fu, H. One-step production of biodiesel from waste cooking oil catalysed by $\mathrm{SO}_{3} \mathrm{H}$-functionalized quaternary ammonium ionic liquid. Curr. Sci. 2016, 110, 2129-2134. [CrossRef]

27. Gao, H.; Ding, L.; Bai, H.; Liu, A.; Li, S.; Li, L. Pitch-based hyper-cross-linked polymers with high performance for gas adsorption. J. Mater. Chem. A 2016, 4, 16490-16498. [CrossRef]

(C) 2019 by the authors. Licensee MDPI, Basel, Switzerland. This article is an open access article distributed under the terms and conditions of the Creative Commons Attribution (CC BY) license (http://creativecommons.org/licenses/by/4.0/). 